\title{
River incision revisited
}

A data-set compilation suggests that measurements of river erosion into rock depend on the observation timescale, casting doubt on whether terraces and other incised landforms faithfully record changes in climate and tectonics. SEE LETTER P.391

\section{ROMAN A. DIBIASE}

$\mathrm{T}$ he pattern and ages of relict landforms, such as terraces, that are incised by rivers provide the best record of changes in Earth's surface elevation over millennial to million-year timescales. As a result, much work has been devoted to determining the age of bedrock landforms ${ }^{1}$ and sediment deposited on terraces ${ }^{2}$ and in caves ${ }^{3}$, to constrain the magnitude and timing of river incision. On page 391 of this issue, Finnegan et al. ${ }^{4}$ challenge the perception that the ages of relict landforms along incised bedrock rivers (Fig. 1) retain a signature of climatic and tectonic forcing. Instead, the authors argue that the intermittent nature of bedrock river incision means that attempts to measure long-term incision rates are inherently biased by the timescale over which they are averaged.

Bedrock rivers set the pace of landscape evolution and form an important connection between Earth's tectonic and climatic systems. As mountain ranges are uplifted, increases in topographic relief cause rivers to incise bedrock towards a balance between erosion and uplift. Furthermore, the ability of rivers to incise rock and transport sediment is controlled by the size and frequency of floods. Such floods are sensitive to changes in climate that may in turn be driven by tectonic processes. In recent decades, provocative hypotheses ${ }^{5}$ regarding the potential coupling of climate, tectonics and erosion have impelled the need for a quantitative understanding of the mechanics of river incision ${ }^{6}$.

The idea of a link between the rates of change in surface elevation and the measurement timescale is well known in stratigraphy; this bias is known as the Sadler effect, after its discovery ${ }^{7}$ by Earth scientist Peter Sadler. In the sedimentary record, depositional history is not continuous, but is broken by gaps of non-deposition or erosion, owing to the dynamics of sedimentary processes. As a

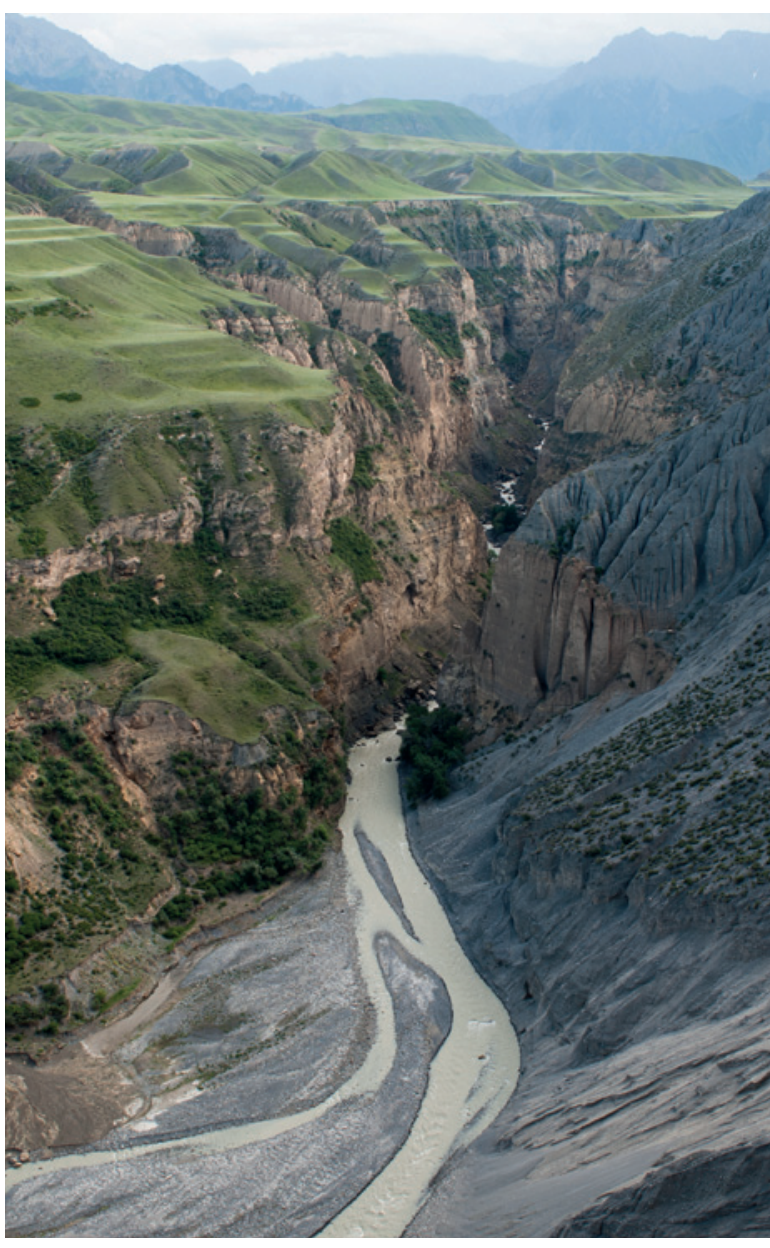

Figure $1 \mid$ A flight of river terraces in the Tian Shan foreland, China. Finnegan et al. ${ }^{4}$ argue that river incision rates into bedrock, determined from dated landforms such as these, are biased by the timescale over which they are measured.

result, measurements of deposition rates over timescales shorter than the longest gap will overestimate long-term averages in a predictable manner ${ }^{8}$. Might a similar bias be present in net erosional landscapes?

Finnegan et al. approached this problem by compiling a global data set of incision records from dated terraces, caves and lava flows. They show that, in general, incision rates decrease with increasing measurement interval. The authors combed published studies for field sites that have multiple levels of dated incised landforms spanning a wide range in age, and analysed records from diverse tectonic settings - including the rapidly uplifting middle gorge of the Indus River in the Himalayas and rivers draining the tectonically quiescent Appalachian Mountains in the eastern United States. They found that, in 11 of 14 locations, apparent incision rates increase towards the present day. This relationship holds across four orders of magnitude in landform age, from thousands to tens of millions of years, and is independent of tectonic setting or landform type.

The researchers reasoned that the observed scaling relationship is due to the intermittency of river incision, and they employed a random-walk model to show this effect. In the model, as the time window of observation increases, so does the likelihood of experiencing a long period without erosion, and an inverse power law scaling between the inferred incision rate and measurement interval emerges. Finnegan et al. propose that the hiatuses in river incision occur when sediment covers and protects the river bed from erosion, and are analogous to gaps in the sedimentary record. This implies that erosional as well as depositional landscapes are subject to an observational bias when deriving rates that average over different time spans.

The similarity in scaling behaviour for sites from a wide range of tectonic settings hints at the existence of a common driver for the perceived acceleration of incision rates, but there are a few factors that complicate this interpretation. First, abandoned flights of terraces and deep valleys that preserve incision markers are the precise landforms expected for landscapes undergoing an actual increase in erosion as a result of changes in climate or tectonics ${ }^{9}$. Further independent information from these landscapes is needed to provide constraints on the plausibility of the steadystate erosion implicitly assumed by Finnegan and colleagues.

Second, although there is little argument that river incision occurs only intermittently, 
and that deposition in response to landslides can protect river beds from eroding over millennial timescales ${ }^{10}$, it is unclear what physical processes drive hiatuses in incision over timescales of 1 million to 10 million years. Such long timescales span multiple glacial-interglacial climate cycles, and may also reflect a connection to deep Earth processes. Perhaps the most intriguing implication of Finnegan and co-workers' study is the idea that longterm rates of landscape lowering may be more sensitive to the frequency and magnitude of depositional events than to the mechanics of river incision into bedrock.

If the authors' findings hold true, a natural question arises: can changes in the pace of landscape evolution be deciphered from net erosional landscapes? Work on depositional landscapes shows that the preservation bias in one-dimensional stratigraphy disappears when the spatial distribution of both preserved sediments and hiatuses within a basin are taken into account ${ }^{11-13}$. By incorporating a similar spatial averaging in erosional landscapes $^{12,13}$, or by accounting for changes in hillslope lowering over time using different chronometers $^{14}$, it may be possible to overcome some of these biases.

Finally, to understand the influence of tectonics, land use or climate change on erosion rates, we need a robust way to compare rates measured over different time intervals. Although this is a challenging task, characterizing the degree to which these rates are unsteady, by studying the processes that control erosion and deposition, is essential for interpreting rates measured over different periods of Earth's history and for predicting future change.

Roman A. DiBiase is in the Division of Geological and Planetary Sciences, California Institute of Technology, Pasadena, California 91125, USA.

e-mail:rdibiase@caltech.edu

1. Leland, J., Reid, M. R., Burbank, D. W., Finkel, R. \& Caffee, M. Earth Planet. Sci. Lett. 154, 93-107 (1998).

2. Anderson, R. S., Repka, J. L. \& Dick, G. S. Geology 24, 47-51 (1996).

3. Granger, D. E., Kirchner, J. W. \& Finkel, R. C. Geology 25, 107-110 (1997).

4. Finnegan, N. J., Schumer, R. \& Finnegan, S. Nature 505, 391-394 (2014).

5. Raymo, M. E. \& Ruddiman, W. F. Nature 359, 117-122 (1992).

6. Whipple, K. X. Nature Geosci. 2, 97-104 (2009).

7. Sadler, P. M. J. Geol. 89, 569-584 (1981).

8. Schumer, R. \& Jerolmack, D. J. J. Geophys. Res. 114, F00A06 (2009).

9. Crosby, B. T. \& Whipple, K. X. Geomorphology 82, 16-38 (2006).

10.Korup, O., Montgomery, D. R. \& Hewitt, K. Proc. Natl Acad. Sci. USA 107, 5317-5322 (2010).

11.Peters, S. E. J. Geol. 114, 391-412 (2006)

12.Sadler, P. M. \& Jerolmack, D. J. in Strata and Time: Probing the Gaps in Our Understanding (eds Smith, D. \& Burgess, P.) (Geol. Soc. Lond. Spec. Publ., in the press).

13.Sadler, P. Geol. Soc. Am. Abstr. Programs 45, 86 (2013).

14. Herman, F. et al. Nature 504, 423-426 (2013).

\section{BIRD FLIGHT}

\section{Fly with a little flap from your friends}

\section{In-air measurements of northern bald ibises flying in a $\mathrm{V}$ formation show that the birds conform to predictions for saving energy by regulating their relative body position and synchronizing their flapping motion. SEE LETTER P.399}

\section{MICHAEL H. DICKINSON} The elegant $\mathrm{V}$ formations of migrating birds provide a picturesque harbinger of summer's end, but why do the birds fly in such a precise formation? There are rumours that Allied bomber pilots during the Second World War noticed that their fuel economy increased when their squadrons flew in a V formation. Although these apocryphal tales have not been confirmed, the energysaving benefits of formation flying have been reported in both civil ${ }^{1}$ and military ${ }^{2}$ aviation. For example, by maintaining one wing tip in the wake of a forward plane, a fighter jet can reduce its energy consumption by up to $18 \%$ (ref. 2). However, exploiting the benefits of formation flight is more challenging for birds than for fixed-wing aircraft — birds

\section{FLORIAN T. MUIJRES \&}

? not only need to adjust their position relative to each other, but also must synchronize their wingbeat patterns ${ }^{3}$. On page 399 of this issue, Portugal et al. ${ }^{4}$ show that at least one bird species exhibits the requisite synchronization of body position and flapping motion to reduce energetic cost during migratory flight.

The principle by which formation flight saves energy derives from the way wings disturb the air as they move $e^{1,5}$. To create lift, wings accelerate airflow over their top surface compared with their bottom surface. Thus, relative to the still air through which they move, wings create a net circular flow of air that is directed rearward over the top surface and forward under the bottom surface. The greater the circulation a wing creates, the higher the lift it produces. At each wing tip, however, the circulation around the wing rolls up into a tip vortex, which extends backward like a tube,

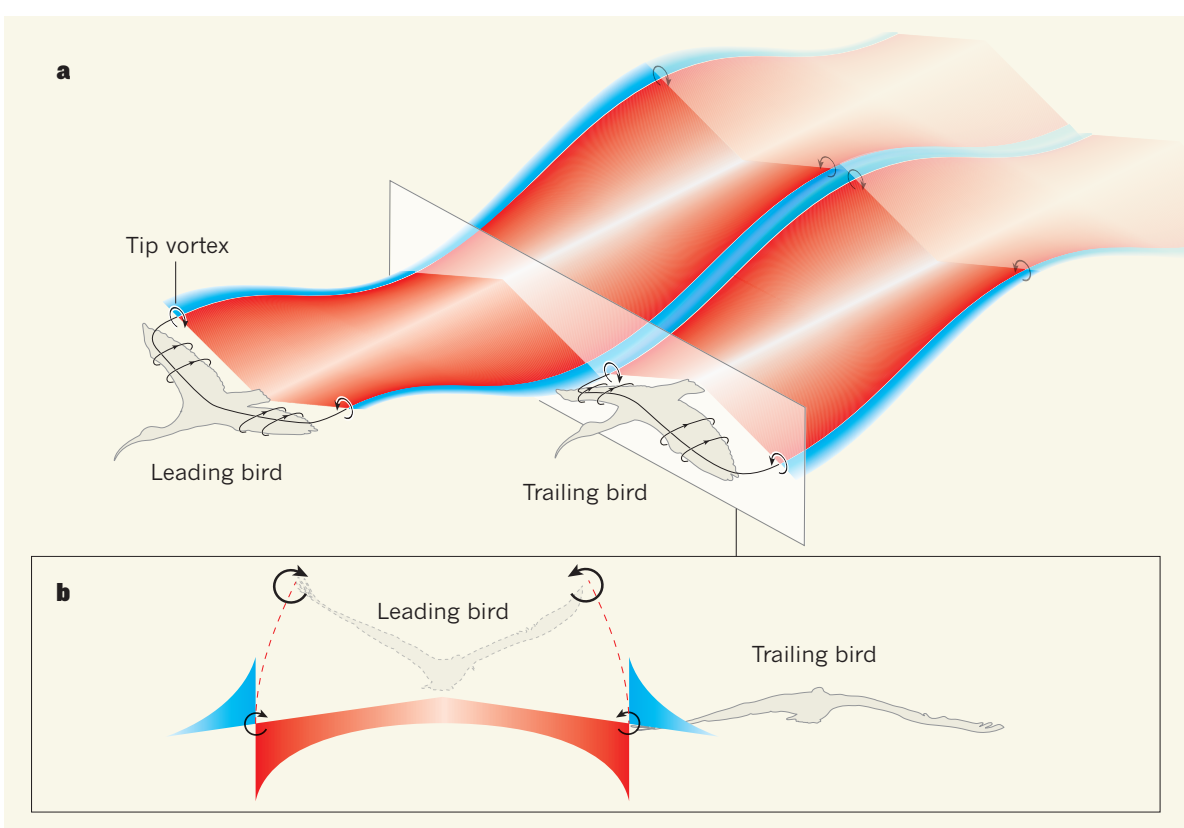

Figure 1 | Spatial synchrony. Flight creates a looping motion of air around a bird's wings; at the wing tips this circulation forms a vortex, creating air movement that extends behind the bird. Airflow down the middle of this wake is directed downwards (the downwash; red), whereas the area outside the tip vortices is a region of upwash (blue). A bird flying behind another bird experiences the aerodynamic forces of the downwash and upwash created by the leading bird (a, side view; b, rear view). Portugal and colleagues ${ }^{4}$ show that northern bald ibises spatially synchronize their wing movements while flying in a $\mathrm{V}$ formation, such that the trailing bird's wing moves through the area of maximum upwash created by the leading bird. This results in more-efficient lift production and energy savings. 